\title{
A Potential Role for Adenosine in the Inhibition of Nonshivering Thermogenesis in the Fetal Sheep
}

\author{
K. T. BALL, T. R. GUNN, G. G. POWER, H. ASAKURA, AND P. D. GLUCKMAN
}

Department of Paediatrics, School of Medicine, University of Auckland, Auckland, New Zealand; and Division of Perinatal Biology, School of Medicine, Loma Linda University, Loma Linda, California 92350

\begin{abstract}
Adenosine is released by the placenta into the fetal circulation and has potent antilipolytic properties in vitro. Nonshivering thermogenesis cannot be demonstrated by cooling fetal sheep in utero but can be induced by supplemental oxygenation and umbilical cord occlusion; this suggests the presence of inhibitor(s) of placental origin. To test whether circulating adenosine could be such an inhibitor, a series of experiments was carried out in nine fetal sheep at 136-145 d gestation. Birth was simulated in utero by sequentially cooling the fetus $2.49 \pm$ $0.23^{\circ} \mathrm{C}$ with no change in the low levels of plasma FFA or glycerol; ventilating with $\mathrm{O}_{2}$ via an exteriorized tracheostomy tube and umbilical cord occlusion. Thermogenic indices rose markedly, and plasma FFA and glycerol concentrations peaked at $725 \pm 88 \mu \mathrm{Eq} / \mathrm{L}(p<0.01)$ and $771 \pm 154 \mu \mathrm{mol} / \mathrm{L},(p<$ 0.001 ), respectively, $\mathrm{O}_{2}$ consumption rose to $20 \pm 2 \mathrm{~mL} / \mathrm{min} / \mathrm{kg}$, and temperature increased $1.99 \pm 0.35^{\circ} \mathrm{C}$. The long-acting adenosine analog $\mathrm{N}_{6}$-(L-2-phenylisopropyl)-adenosine (PIA) was then infused (90 $\mu \mathrm{g} / \mathrm{kg}$ bolus, then $300 \mu \mathrm{g} / \mathrm{kg} / \mathrm{h}$ for $30 \mathrm{~min}$ ); plasma FFA and glycerol decreased to $265 \pm 56 \mu \mathrm{Eq} / \mathrm{L}(p<$
\end{abstract}

When a fetal sheep is cooled in utero, nonshivering thermogenesis is not initiated, as evidenced by the failure of plasma FFA and glycerol concentrations to increase and the lack of additional heat production by brown adipose tissue (1). The failure of this thermogenic response is observed despite the capability of ovine brown fat cells to respond to thermogenic stimuli in vitro (2) and despite the ability of prematurely delivered and term-delivered lambs to thermoregulate (3). These findings indicate that brown adipose tissue is competent but unresponsive before birth.

The stimulus or combination of stimuli that may account for the initiation of nonshivering thermogenesis within minutes of birth is unknown. Although a number of potential stimuli have been tested and found to be necessary, none has proved sufficient. For example, cooling and increased oxygenation of the fetal sheep $(1,4-7)$ and an intact sympathetic nervous

Received January 10, 1994; accepted November 8, 1994

Correspondence: Professor Tania R. Gunn, Department of Paediatrics, School of Medicine, University of Auckland, Private Bag 92019, Auckland, New Zealand.

Supported by grants from the Health Research Council of New Zealand, the Foundation for the Newborn, and the Child Health and Human Development Grant HD-16827.
$0.003)$ and $477 \pm 102 \mu \mathrm{mol} / \mathrm{L}(p<0.04)$, respectively; $\mathrm{O}_{2}$ consumption fell rapidly to $4.5 \pm 0.3 \mathrm{~mL} / \mathrm{min} / \mathrm{kg}(p<0.01)$; temperature decreased $1.89 \pm 0.39^{\circ} \mathrm{C}(p<0.001)$; and fetal arterial BP decreased to $38 \pm 5 \mathrm{~mm} \mathrm{Hg}(p<0.004)$ in $30 \mathrm{~min}$. A stepped dose-response study was performed in three fetal sheep. Birth was simulated in utero and then PIA was administered in escalating doses for five sequential 30 -min periods with 60 -min intervals in between, starting at $0.08 \mu \mathrm{g} / \mathrm{kg}$ bolus. The fetal arterial blood pressure was not affected by any of the relatively low doses of PIA used; however, all of the doses of PIA inhibited nonshivering thermogenesis in a dose-dependent manner. These results are consistent with adenosine suppression of brown adipose tissue thermogenesis in utero and suggest that adenosine may be an inhibitor of placental origin. (Pediatr Res 37: 303-309, 1995)

\section{Abbreviations \\ PIA, $\mathrm{N}_{6}$-(L-2-phenylisopropyl)-adenosine}

system (8) are necessary for thermogenesis, but they fail to evoke responses comparable to those seen after birth. Only after the umbilical cord has been occluded do the thermogenic responses increase appreciably $(1,4-7)$. Such observations suggest that the onset of nonshivering thermogenesis in the fetal lamb is dependent on the removal of an inhibitor of placental origin. The removal of the inhibitor after interruption of the umbilical circulation at birth would enable thermogenesis to increase appreciably.

Adenosine is a compound released by the placenta $(9,10)$, is present in high concentrations in fetal plasma $(11,12)$, has a short half-life in circulating blood (13), and inhibits catecholamine-stimulated lipolysis in brown adipose tissue in vitro $(14,15)$. Thus, we hypothesized that the high circulating levels of adenosine in the fetus would inhibit nonshivering thermogenesis in utero, and then the declining levels upon removal of the umbilical circulation would enable the initiation of thermogenesis. We examined the hypothesis by simulating the birth of fetal sheep in utero and then by infusing the adenosine analog PIA after umbilical cord occlusion. We reasoned that return of thermogenic indices to fetal levels would support the hypothesis. 


\section{METHODS}

\section{Surgical and Postoperative Procedures}

The surgical procedures were undertaken under general anesthesia (halothane 1.5-2\%) in pregnant Romney ewes (mated to Suffolk rams) at 135-145 d gestation. As previously described (1), an external cooling coil was placed around the fetal thorax. Calibrated thermistors were advanced nasally into the stomach to record core body temperature. A tracheal cannula was inserted and connected to a length of tubing to ventilate the fetus. An umbilical tape occluder was placed loosely around the umbilical cord, and polyvinyl catheters were inserted into the fetal common carotid artery, external jugular vein, and amniotic sac. The fetal thorax and head were then eased back into the uterus. The afferent and efferent limbs of the cooling coil, thermistor leads, tracheal tube, occluder, and catheters were exteriorized through the maternal flank. A thermistor and catheter were also placed in a maternal tarsal vein.

After the operation the ewe was housed in a metabolic cage at a constant temperature $\left(16^{\circ} \mathrm{C}\right)$ and humidity $(50 \%)$ and given free access to water and hay supplemented by concentrates. The experiments were performed while the ewe stood quietly in a metabolic cage. All studies were performed $24 \mathrm{~h}$ after surgery in fetuses with normal arterial blood $\mathrm{pH}(\geq 7.30)$, $\mathrm{Po}_{2}(\geq 2.93 \mathrm{kPa})$, and $\mathrm{PCO}_{2}(\leq 7.47 \mathrm{kPa})$. Our previous studies done afer this period of postoperative recovery with hormone and metabolite measurements showed adequate fetal recovery to induce thermogenesis $(1,4-7)$.

\section{Experimental Procedures}

General procedures. Fetal arterial heparinized blood samples (2.1-2.6 mL) were collected anaerobically at 5- to 15-min intervals and were replaced isovolumetrically with isotonic saline. When a small fetus was studied, the erythrocytes removed during sampling were returned to the fetal circulation. Blood samples were analyzed promptly for $\mathrm{Hb}$ levels (Radiometer OSM2 hemoximeter, Copenhagen, Denmark) and for $\mathrm{pH}, \mathrm{Po}_{2}$, and $\mathrm{PCO}_{2}$ (Radiometer ABL2 or ABL330), which were corrected to core temperature. Plasma was separated after centrifugation and stored at $-20^{\circ} \mathrm{C}$ for later analysis.

Fetal and maternal temperature measurements were made by connecting the thermistors to a microprocessor-controlled unit capable of linear temperature measurement from 32 to $43^{\circ} \mathrm{C}$ with a resolution of $0.01^{\circ} \mathrm{C}$ as previously described (16). Recordings of fetal arterial blood pressure, tracheal pressure (both corrected for amniotic pressure), amniotic pressure, and heart rate were displayed on a polygraph. Recordings were begun $4 \mathrm{~h}$ after surgery and continued until the termination of the study.

Simulation of birth in utero. As described previously (1), cooling was induced by passing cold water $\left(14-19^{\circ} \mathrm{C}\right)$ through the fetal external thoracic cooling coil at a rate of 140-280 $\mathrm{mL} / \mathrm{min}$. This rate was adjusted to cause a decrease in fetal core temperature of approximately $2^{\circ} \mathrm{C}$ in the first $60 \mathrm{~min}$ of cooling, and this rate of cooling was maintained throughout the rest of the study. After draining the tracheal cannula and tubing of fluid, ventilation was begun with $\mathrm{O}_{2}$ saturated with water vapor, using a respiratory pump (Harvard, model 607, Harvard Apparatus Co., Inc., South Natick, MA). Effective ventilation was maintained typically with a respiratory frequency of 20-30 breaths per minute and peak-inspiratory and endexpiratory pressures $30-40$ and $5-10 \mathrm{~mm} \mathrm{Hg}$ higher than amniotic fluid pressure, respectively. Fetal arterial $\mathrm{O}_{2}$ tension increased to $82.9 \pm 25 \mathrm{~mm} \mathrm{Hg}(11.1 \pm 3.3 \mathrm{kPa})$, whereas $\mathrm{CO}_{2}$ levels and $\mathrm{pH}$ were unchanged. The umbilical cord was occluded by pulling, the loop tight around the cord to stop all umbilical blood flow. In protocol 1 and the latter doses in protocol 2, PIA administration tended to decrease $\mathrm{O}_{2}$ consumption and $\mathrm{CO}_{2}$ production. To maintain a constant arterial $\mathrm{PCO}_{2}$ and prevent respiratory alkalosis, the respiratory frequency was then reduced to $10-20$ breaths per minute.

\section{Protocol 1: Birth Simulation Followed by Administration of the Adenosine Agonist PIA}

After a 30 -min control period ( -30 to 0$)$, the fetus was cooled $(0-360)$. Sixty minutes after cooling commenced, the fetus was ventilated with $\mathrm{O}_{2}(60-360)$. The umbilical cord was occluded (120-360) 60 min later. Ninety minutes after cord occlusion, the nonmetabolizable adenosine analog PIA (Sigma Chemical Co., St. Louis, MO; $90 \mu \mathrm{g} / \mathrm{kg}$ bolus, then 300 $\mu \mathrm{g} / \mathrm{kg} / \mathrm{h}$ ) was administered i.v. to the fetus over $30 \mathrm{~min}(210-$ 240), and the responses were monitored during the following 120-min interval until the termination of the experiment (240$360 \mathrm{~min}$ ).

\section{Protocol 2: Birth Simulation Followed by Administration of PIA at Varying Doses}

To separate the inhibition of nonshivering thermogenesis due to PIA administration from the hypotension due to PIA, a stepped dose-response study was performed in three fetal sheep. The fetus was cooled $(0-660)$ after a 30 -min control period ( -30 to 0$)$. Ventilation with $\mathrm{O}_{2}(60-660)$ commenced 60 min after the initiation of cooling. Sixty minutes later the umbilical cord was occluded (120-660). The adenosine analog PIA was administered 90 min later in escalating doses for five sequential 30 -min periods $\left(\mathrm{P}_{1}-\mathrm{P}_{5}\right)$ with 60 -min intervals in between starting with a dose chosen to be about [1/1000] that used in protocol $1\left(\mathrm{P}_{1}: 0.08 \mu \mathrm{g} / \mathrm{kg}\right.$ bolus, then $0.25 \mu \mathrm{g} / \mathrm{kg} / \mathrm{h} ; \mathrm{P}_{2}$ : $0.15 \mu \mathrm{g} / \mathrm{kg}$ bolus, then $0.5 \mu \mathrm{g} / \mathrm{kg} / \mathrm{h} ; \mathrm{P}_{3}: 0.8 \mu \mathrm{g} / \mathrm{kg}$ bolus, then $2.5 \mu \mathrm{g} / \mathrm{kg} / \mathrm{h} ; \mathrm{P}_{4}: 1.5 \mu \mathrm{g} / \mathrm{kg}$ bolus, then $5 \mu \mathrm{g} / \mathrm{kg} / \mathrm{h} ; \mathrm{P}_{5}: 8 \mu \mathrm{g} / \mathrm{kg}$ bolus, then $25 \mu \mathrm{g} / \mathrm{kg} / \mathrm{h}$ ).

After completion of each study, the fetus and ewe were killed humanely with an overdose of sodium pentobarbitone. The location of the thermistors was verified, as was the complete occlusion of the umbilical cord. The thermistors were then recalibrated to establish that their characteristics had not changed during implantation.

All of these procedures were approved by the Animal Ethics Committees of the University of Auckland.

\section{Analytical Procedures}

Plasma FFA concentrations were determined as described previously (17) using a sample size of $0.1 \mathrm{~mL}$ to increase 
sensitivity. The within-assay coefficient of variation was $14.9 \%$, the between-assay coefficient of variation was $23.3 \%$, and the assay sensitivity was $40 \mu \mathrm{Eq} / \mathrm{L}$. The enzymatic method of Pinter et al. (18) was used to measure plasma glycerol levels. The within- and between-assay coefficients of variation were 14.3 and $20.2 \%$, respectively, and the assay sensitivity was $50 \mu \mathrm{mol} / \mathrm{L}$.

The volume change in the spirometer over time was used as an index of $\mathrm{O}_{2}$ uptake rate by the fetal lungs. Slopes were averaged during 15-min intervals and the volume expressed as milliliters of $\mathrm{O}_{2}$ at STPD. Before cord occlusion, pulmonary $\mathrm{O}_{2}$ uptake was influenced by placental as well as fetal tissue, so that only after cord occlusion could pulmonary $\mathrm{O}_{2}$ uptake be equated strictly to fetal $\mathrm{O}_{2}$ consumption.

The results are given as mean \pm SEM. Repeated measures analysis of variance was used to determine the significance of change in response to various stimuli. The significance of each added stimulus was tested post hoc by paired $t$ test between the value immediately before and at the end of the experimental period with use of the Bonferroni correction to allow for multiple comparisons.

\section{RESULTS}

\section{Birth Simulation Followed by Administration of PIA (Protocol 1)}

Nine fetal sheep of 136 to $145 \mathrm{~d}$ gestation were studied. Their mean weight was $4.16 \pm 0.19 \mathrm{~kg}$. Changes in the fetal core temperature, arterial blood pressure, $\mathrm{pH}$, and blood gases are summarized in Table 1 . The time course of the temperature and major indices of nonshivering thermogenic activity are illustrated in Figure 1. Note that, although plasma FFA and glycerol are only indicators of lipolysis, their plasma concentrations correlate well with other indices of nonshivering thermogenesis, including the extent to which brown fat temperature exceeds core temperature and the increase in $\mathrm{O}_{2}$ consumption during thermogenesis (1).

Control period. During the control period the mean values for arterial blood pressure, core temperature, plasma FFA, and glycerol were within the normal range.

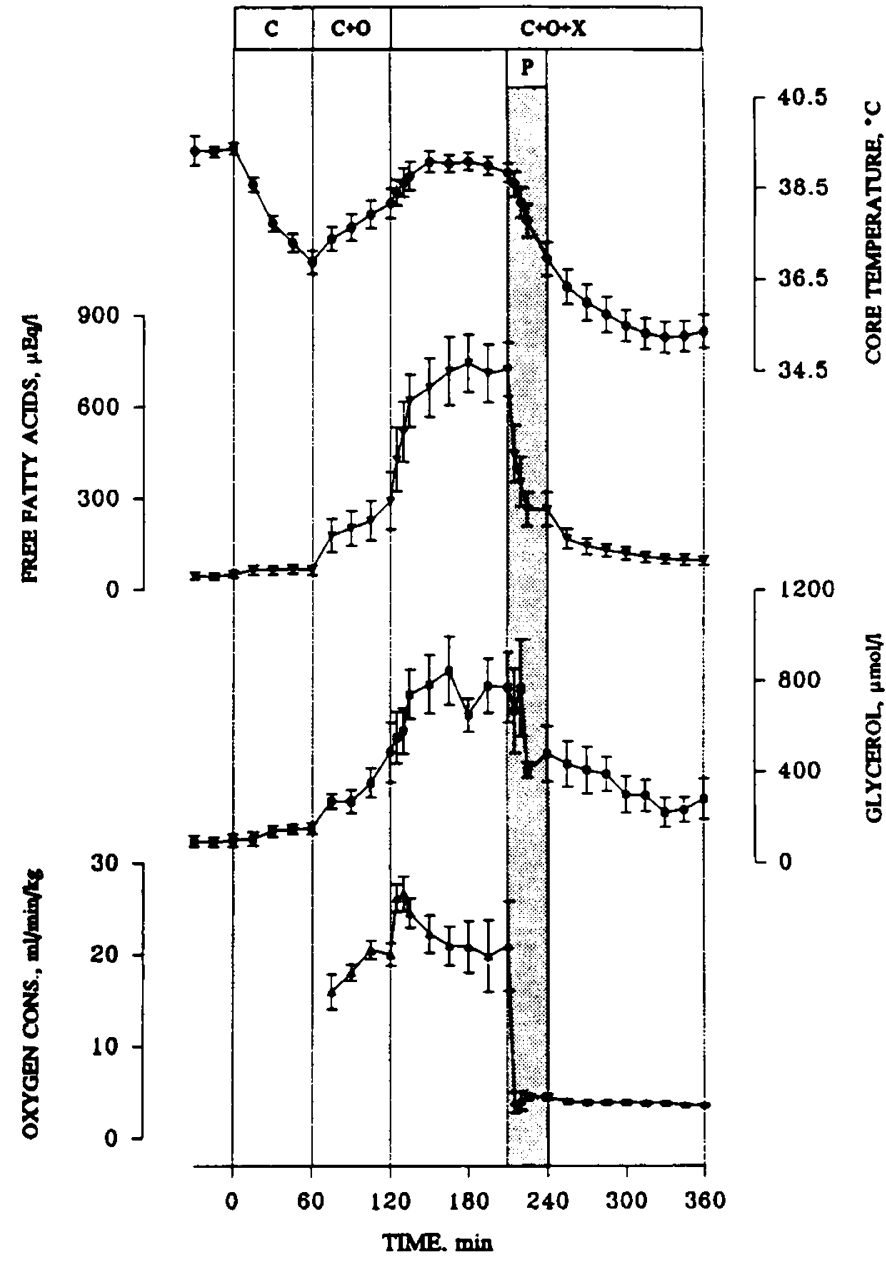

Figure 1. Effect of birth simulation followed by administration of the longacting adenosine analog PIA on core temperature, plasma FFA and glycerol concentrations, and $\mathrm{O}_{2}$ consumption in the fetal sheep. Results are the mean \pm SEM of nine experiments. $C$, cold exposure; $O$, ventilation with $\mathrm{O}_{2} ; P$, phenylisopropyladenosine administration; $X$, umbilical cord occlusion.

Cold exposure. Fetal core temperature decreased rapidly to $36.85 \pm 0.26^{\circ} \mathrm{C}$, averaging $2.49 \pm 0.23^{\circ} \mathrm{C}(p<0.001)$ less than the control mean. Plasma FFA $(65 \pm 16 \mu \mathrm{Eq} / \mathrm{L})$ and glycerol $(151 \pm 25 \mu \mathrm{mol} / \mathrm{L})$ concentrations remained at low levels.

Table 1. Effect of birth stimulation followed by administration of adenosine analog PIA on core temperature, arterial blood pressure, pH, and blood gases

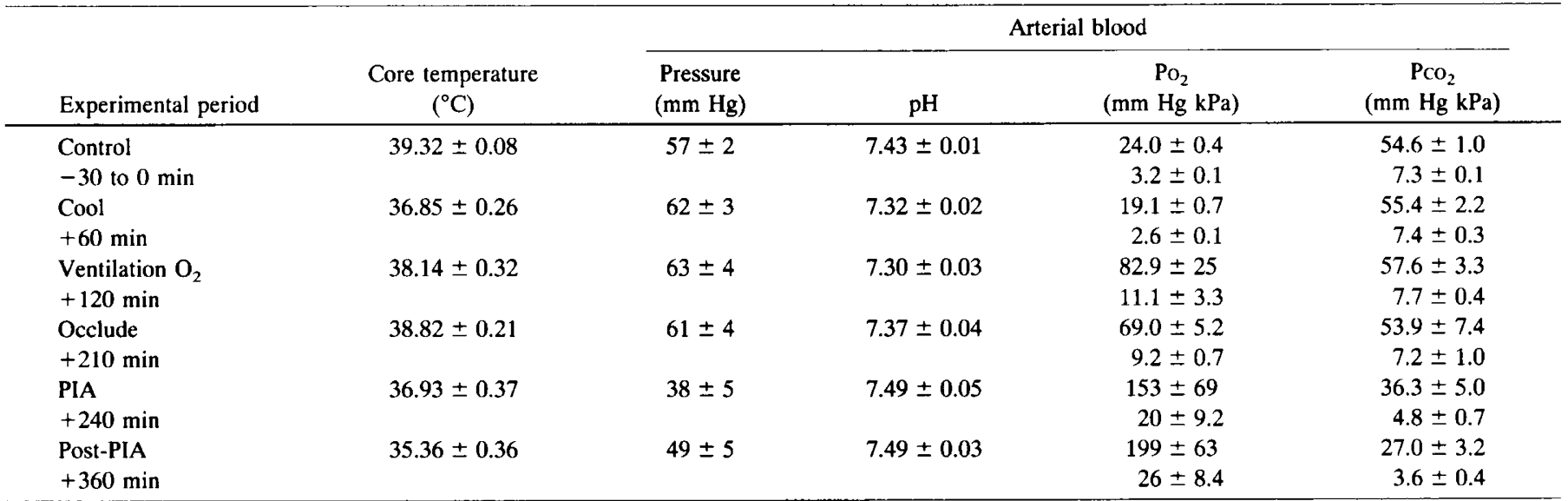

Results are mean \pm SEM of nine fetal sheep from protocol 1. 
Ventilation with $\mathrm{O}_{2}$. Within minutes of the elevation of arterial $\mathrm{O}_{2}$ levels, the fetal thermogenic responses became apparent. Fetal core temperature reversed its fall and increased $1.36 \pm 0.37^{\circ} \mathrm{C}(p<0.01)$ to $38.14 \pm 0.32^{\circ} \mathrm{C}$. Plasma levels of FFA and glycerol also increased rapidly, averaging $293 \pm 95$ $\mu \mathrm{Eq} / \mathrm{L}, 350 \%(p<0.001)$ and $485 \pm 132 \mu \mathrm{mol} / \mathrm{L}, 221 \%(p<$ 0.05 ) higher than cooled levels, respectively, after $60 \mathrm{~min}$ of supplemental $\mathrm{O}_{2}$.

Umbilical cord occlusion. After umbilical cord occlusion, the fetal core temperature increased further by $0.87 \pm 0.24^{\circ} \mathrm{C}$ to $38.82 \pm 0.21^{\circ} \mathrm{C}$. Thermogenic responses were clearly evident as plasma FFA and glycerol concentrations rose to plateau at $725 \pm 88 \mu \mathrm{Eq} / \mathrm{L}$ and $771 \pm 154 \mu \mathrm{mol} / \mathrm{L}$, values that were $147 \%(p<0.001)$ and $59 \%(p<0.02)$ greater than ventilation values, respectively. Within $30 \mathrm{~min}$ of cord occlusion, $\mathrm{O}_{2}$ consumption peaked at $27 \pm 2 \mathrm{~mL} / \mathrm{min} / \mathrm{kg}$ and thereafter declined slowly to $20 \pm 2 \mathrm{~mL} / \mathrm{min} / \mathrm{kg}$.

PIA administration. Within minutes of PIA administration, the fetal mean arterial blood pressure decreased to $38 \pm 5 \mathrm{~mm}$ $\mathrm{Hg}(p<0.004)$. The pressure recovered to $49 \pm 5 \mathrm{~mm} \mathrm{Hg}$ during the postinfusion period $(p<0.002)$. PIA infusion induced a concurrent decrease in the fetal core temperature during the 30-min infusion $(p<0.001)$, plateauing during the postinfusion period at approximately $35.30 \pm 0.33^{\circ} \mathrm{C}(p<$ $0.001)$. Other indices of nonshivering thermogenesis became depressed after administration of PIA: plasma FFA and glycerol concentrations decreased sharply to $265 \pm 56 \mu \mathrm{Eq} / \mathrm{L}(p<$ $0.003)$ and $477 \pm 102 \mu \mathrm{mol} / \mathrm{L}(p<0.04)$, respectively, then declined more gradually during the post-PIA administration interval. Likewise, PIA infusion was followed by a rapid decline in $\mathrm{O}_{2}$ consumption to $4.5 \pm 0.3 \mathrm{~mL} / \mathrm{min} / \mathrm{kg}$, a level significantly less $(p<0.01)$ than basal levels reported previously using sirnilar methodology (1).

\section{Birth Simulation Followed by Administration of PIA at Varying Doses (Protocol 2)}

To further investigate whether the inhibition of nonshivering thermogenesis subsequent to PIA administration is due to the direct effect of PIA or by the PIA-induced decrease in arterial blood pressure, a dose-response study was performed. Three fetal sheep were studied at 138-142 d gestation with a mean weight of $4.73 \pm 0.64 \mathrm{~kg}$. We included only three fetal sheep in this protocol because the blood pressure did not fall after any of the 15 sequential low doses of PIA studied, whereas thermogenic indices were inhibited by all of these PIA doses. Table 2 and Figure 2 illustrate the time course of the fetal core temperature, arterial blood pressure, $\mathrm{pH}$, blood gases, and major indices of nonshivering thermogenic activity.

The cardiovascular and thermogenic responses to cold exposure, ventilation with $\mathrm{O}_{2}$, and umbilical cord occlusion were similar to those observed in protocol 1 . The infusion of PIA induced a stepwise and dose-dependent decrease in fetal core temperature, FFA and glycerol concentrations, and $\mathrm{O}_{2}$ consumption during each of the dose periods. The fetal arterial blood pressure was not affected by any of the relatively low

Table 2. Effect of birth stimulation followed by administration of PIA at various doses on core temperature, arterial blood pressure, pH, and blood gases

\begin{tabular}{|c|c|c|c|c|c|}
\hline \multirow[b]{2}{*}{ Experimental period } & \multirow[b]{2}{*}{$\begin{array}{c}\text { Core temperature } \\
\left({ }^{\circ} \mathrm{C}\right)\end{array}$} & \multicolumn{4}{|c|}{ Arterial blood } \\
\hline & & $\begin{array}{l}\text { Pressure } \\
(\mathrm{mm} \mathrm{Hg})\end{array}$ & $\mathrm{pH}$ & $\begin{array}{c}\mathrm{Po}_{2} \\
(\mathrm{~mm} \mathrm{Hg} \mathrm{kPa})\end{array}$ & $\begin{array}{c}\mathrm{Pco}_{2} \\
(\mathrm{~mm} \mathrm{Hg} \mathrm{kPa})\end{array}$ \\
\hline Control & $39.18 \pm 0.08$ & $59 \pm 3$ & $7.44 \pm 0.01$ & $22.9 \pm 0.7$ & $53.2 \pm 0.8$ \\
\hline-30 to $0 \mathrm{~min}$ & & & & $3.1 \pm 0.1$ & $7.1 \pm 0.1$ \\
\hline Cool & $37.51 \pm 0.48$ & $66 \pm 2$ & $7.41 \pm 0.01$ & $15.7 \pm 1.2$ & $54.1 \pm 1.8$ \\
\hline$+60 \mathrm{~min}$ & & & & $2.1 \pm 0.2$ & $7.2 \pm 0.2$ \\
\hline Ventilation $\mathrm{O}_{2}$ & $38.36 \pm 0.40$ & $62 \pm 3$ & $7.44 \pm 0.03$ & $63.2 \pm 7.9$ & $45.4 \pm 4.0$ \\
\hline$+120 \mathrm{~min}$ & & & & $8.4 \pm 1.1$ & $6.1 \pm 0.5$ \\
\hline Occlude & $39.32 \pm 0.16$ & $70 \pm 7$ & $7.49 \pm 0.04$ & $87.1 \pm 16.2$ & $42.8 \pm 2.3$ \\
\hline$+210 \mathrm{~min}$ & & & & $11.6 \pm 2.2$ & $5.7 \pm 0.3$ \\
\hline $\mathrm{PIA}_{1}$ & $38.79 \pm 0.28$ & $71 \pm 4$ & $7.49 \pm 0.05$ & $67.6 \pm 10.7$ & $44.2 \pm 5.9$ \\
\hline$+240 \mathrm{~min}$ & & & & $9.0 \pm 1.4$ & $5.9 \pm 0.8$ \\
\hline Post-PIA 1 & $38.89 \pm 0.21$ & $73 \pm 5$ & $7.45 \pm 0.07$ & $57.5 \pm 5.0$ & $46.6 \pm 5.3$ \\
\hline$+300 \mathrm{~min}$ & & & & $7.7 \pm 0.7$ & $6.2 \pm 0.7$ \\
\hline Post-PIA 2 & $38.42 \pm 0.32$ & $69 \pm 5$ & $7.50 \pm 0.05$ & $65.6 \pm 5.7$ & $36.8 \pm 1.8$ \\
\hline$+330 \mathrm{~min}$ & & & & $8.8 \pm 0.8$ & $4.9 \pm 0.2$ \\
\hline Post-PIA 2 & $38.40 \pm 0.27$ & $68 \pm 2$ & $7.46 \pm 0.04$ & $54.4 \pm 8.4$ & $41.9 \pm 2.2$ \\
\hline$+390 \mathrm{~min}$ & & & & $7.3 \pm 1.1$ & $5.6 \pm 0.3$ \\
\hline Post-PIA 3 & $37.32 \pm 0.40$ & $66 \pm 4$ & $7.49 \pm 0.05$ & $61.4 \pm 21.1$ & $38.5 \pm 6.2$ \\
\hline$+420 \mathrm{~min}$ & & & & $8.2 \pm 2.8$ & $5.1 \pm 0.8$ \\
\hline Post-PIA 3 & $36.86 \pm 0.73$ & $65 \pm 4$ & $7.41 \pm 0.07$ & $44.4 \pm 12.0$ & $50.0 \pm 7.3$ \\
\hline$+480 \min$ & & & & $5.9 \pm 1.6$ & $6.7 \pm 1.0$ \\
\hline Post-PIA 4 & $36.89 \pm 0.62$ & $59 \pm 19$ & $7.50 \pm 0.06$ & $45.9 \pm 6.6$ & $39.0 \pm 5.7$ \\
\hline$+510 \mathrm{~min}$ & & & & $6.1 \pm 0.9$ & $5.2 \pm 0.8$ \\
\hline Post-PIA & $36.71 \pm 0.83$ & $69 \pm 9$ & $7.43 \pm 0.02$ & $55.0 \pm 2.1$ & $46.3 \pm 4.3$ \\
\hline$+570 \mathrm{~min}$ & & & & $7.3 \pm 0.3$ & $6.2 \pm 0.6$ \\
\hline Post-PIA & $36.43 \pm 0.60$ & $62 \pm 9$ & $7.53 \pm 0.01$ & $51.5 \pm 4.2$ & $37.8 \pm 0.2$ \\
\hline$+600 \mathrm{~min}$ & & & & $6.9 \pm 0.6$ & $5.0 \pm 0.1$ \\
\hline
\end{tabular}

Results are mean \pm SEM of three fetal sheep (protocol 2). 


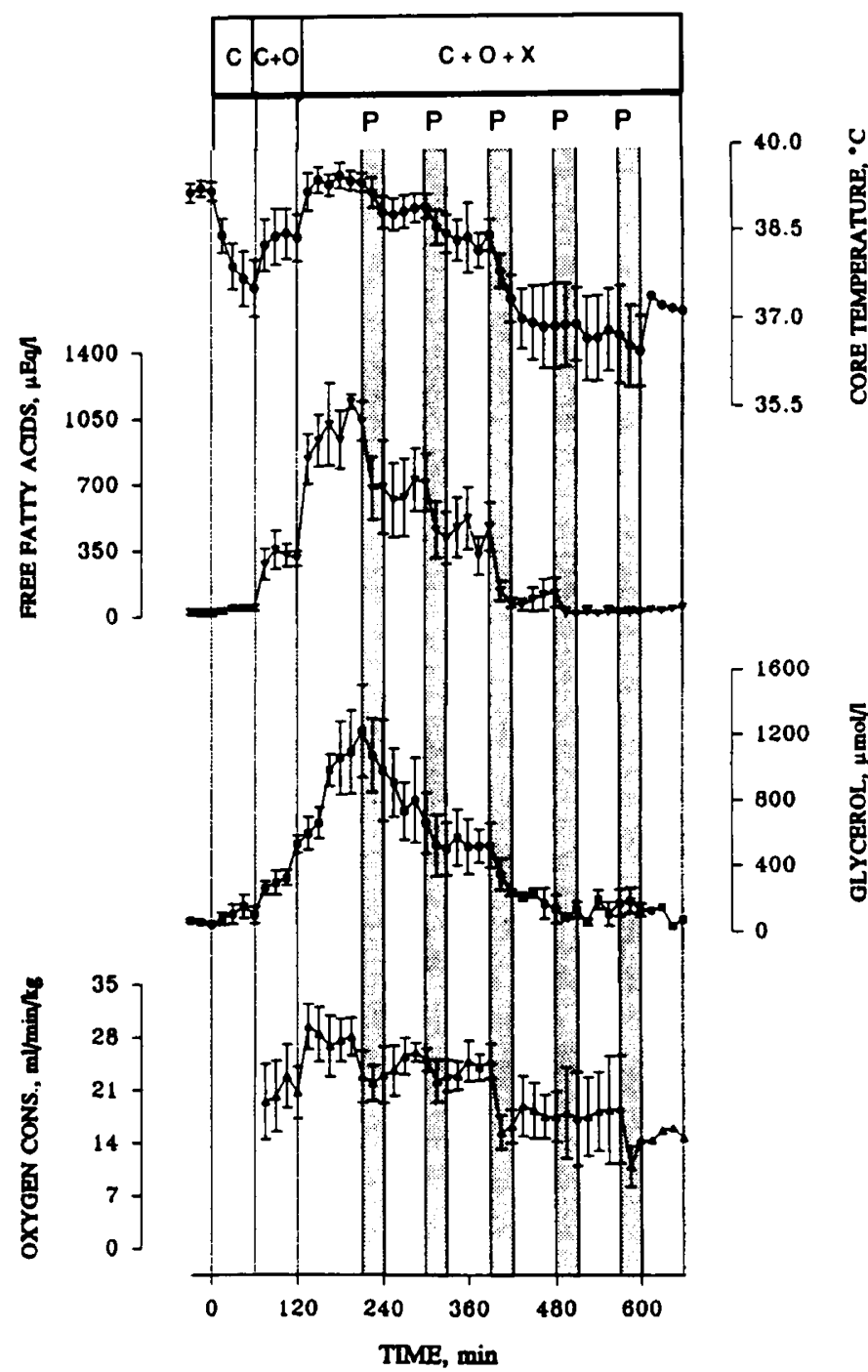

Figure 2. Effect of birth simulation followed by administration of PIA at varying doses on core temperature, plasma FFA and glycerol concentrations, and $\mathrm{O}_{2}$ consumption in the fetal sheep. Results are the mean \pm SEM of three experiments. $C$, cold exposure; $O$, ventilation with $\mathrm{O}_{2} ; P_{1-5}$, phenylisopropyladenosine administration; $X$, umbilical cord occlusion.

doses of PIA used. However, all of the PIA doses at least partially inhibited nonshivering thermogenesis in a dosedependent manner. The lower three doses of PIA progressively reduced the core temperature and FFA and glycerol concentrations, whereas the higher two doses of PIA completely inhibited nonshivering thermogenesis as indicated by the FFA and glycerol levels.

\section{DISCUSSION}

At birth the major changes of cooling, increased oxygenation, and separation from the placental blood flow occur rapidly, and it has not been possible to study the effects of the individual factors. By stimulating birth in utero, it is possible to separate each stimulus and to study the effects sequentially. In this study cooling the fetal sheep failed to cause plasma FFA and glycerol concentrations to increase, confirming the results of our previous studies that showed that when the fetal sheep is cooled in utero it produces little heat from nonshivering thermogenesis in brown fat (1). This failure to respond is observed despite the capability of ovine fetal brown fat cells to respond to thermogenic stimuli in vitro (2) and the ability of prematurely delivered and term-delivered lambs to produce significant amounts of additional heat from nonshivering thermogenesis in brown fat (3). Ventilation with $\mathrm{O}_{2}$ in our study caused modest thermogenic responses, and umbilical cord occlusion was followed by further increases in fetal core temperature, plasma FFA and glycerol concentrations, and $\mathrm{O}_{2}$ consumption. The directional changes in the thermogenic indices were the same in all animals. In this study, as in our previous studies $(1,4-7)$, only after cooling of the fetal skin, augmented oxygenation, and separation from the placenta do nonshivering thermogenic responses increase to approach levels achieved in newborn lambs. We postulated that the placenta produces a thermogenic inhibitor(s) that circulates before birth and tonically suppresses nonshivering thermogenesis.

The possible candidates for such a thermogenic inhibitor of thermogenesis include adenosine, a compound synthesized by the placenta and known to have antilipolytic properties $(9,10)$. Because adenosine is metabolized rapidly (13), we used PIA, a potent, long-acting adenosine analog. We first investigated the effects of infusion of PIA during birth stimulation in utero. In this study PIA was associated with a rapid decrease in all indices of nonshivering thermogenic activity to basal levels. This result is consistent with a thermogenic regulatory role for adenosine in the perinatal period. However, a decline in fetal blood pressure, which averaged $12 \mathrm{~mm} \mathrm{Hg}$, occurred concurrently; this might itself be the cause of such an inhibition of thermogenesis because a substantial increase in blood flow through brown adipose tissue $(19,20)$ normally accompanies nonshivering thermogenesis. Accordingly, we performed further experiments to separate the direct inhibitory effects of low doses of PIA on blood pressure and the consequent indirect alteration of thermogenesis. In this instance a thermogenic suppression could be demonstrated without any decrease in blood pressure. In this, as in the first protocol, there was a uniform directional change in the thermogenic indices in response to each individual dose of PIA in each animal. The indices of nonshivering thermogenesis were reduced at even [1/1000] of the dose of PIA used in protocol 1. Overall, these data lend further support to the hypothesis that adenosine serves as an inhibitor of nonshivering thermogenesis before the loss of the placental circulation at birth and that the inhibition is likely to be specific to brown fat and unrelated to systemic changes such as a decrease in blood pressure.

Adenosine is a neuromodulator with widespread regulatory functions particularly to maintain $\mathrm{O}_{2}$ supply and prevent overstimulation of the cell when the energy supply is insufficient; cells under stress can release adenosine, which modulates the function of the cell in an autocrine manner (15). Adenosine controls blood flow through stimulatory or inhibitory adenosine receptors on blood vessels (21). In high doses, hypotension occurs, and this effect was apparent in our first protocol. The regulatory role of adenosine as an inhibitor of $\beta$ - and $\alpha$-adrenergic-stimulated lipolysis in brown fat cells is well documented $(14,15)$. In brown adipose tissue, adenosine inhibits $\beta_{3}$-adrenergic-activated adenylate cyclase activity (22, 
23) through the interaction with the specific purinergic cell surface $A_{1}$ receptors. Two classes of purinergic receptors were originally described (24): adenosine binds preferably to the $P_{1}$ receptor, whereas ATP binds to the $P_{2}$ receptor. There were two subtypes of the $P_{1}$ receptor described initially that have been renamed $A_{1}$ and $A_{2}(25,26)$. Adenosine $A_{1}$ and adenosine $A_{2}$ receptors are distinguished by the relative and absolute potencies of R-PIA and 5'-N-ethylcarboxamide adenosine: the affinity of the adenosine $A_{1}$ receptor for R-PIA is greater than that for $5^{\prime}$-N-ethylcarboxamide adenosine and the reverse for the adenosine $A_{2}$ receptor (26). The adenosine $A_{1}$ receptor is tightly coupled to the inhibitory $G_{i}$-protein (26). Adenosine $A_{1}$ receptor activation results in inhibition of adenyl cyclase activity reducing the intracellular cAMP concentration (25). Thus PIA, an extremely potent agonist that is selective for $A_{1}$ type receptors on brown fat cells $(27,28)$, was used in our study.

The $\alpha$-adrenergic nonshivering thermogenic component (29, 30 ) is less responsive to the inhibitory actions of adenosine than is the $\beta$-adrenergic component (31) and is not related to adenylate cyclase activity $(32,33)$, suggesting the presence of a second mechanism unrelated to adenylate cyclase augmented by activation of adenosine receptors on brown fat cells (31). There are other potential mechanisms to explain the inhibitory effect of adenosine on nonshivering thermogenesis. The adenosine $A_{1}$ receptors are also coupled to other effector systems such as $\mathrm{K}^{+}$channels and phospholipases (26). The effect of adenosine on ATPase activity is an alternative hypothesis, especially because of the close association of the decrease in $\mathrm{O}_{2}$ uptake and the metabolic effects; in future studies phosphorus magnetic resonance could evaluate whether the elevation in intracellular inorganic phosphorus is inhibited by adenosine or its analog.

The major route for elimination of extracellular adenosine is by cellular reuptake through nucleoside carriers, thereby decreasing the levels at the receptor sites. In the cell, adenosine is mainly eliminated by the enzyme adenosine deaminase, which degrades adenosine to inosine. Adenosine kinase, an enzyme that phosphorylates intracellular adenosine to AMP, is another mechanism for elimination. When thermogenesis is increased in brown fat during adrenergic stimulation, adenosine is released from the stimulated brown fat cells (34) and acts as a feedback inhibitor of adenyl cyclase activity, lipolysis, and respiration $(15,34)$. Because adenosine is a potent vasodilator as well as an antilipolytic, it may perform an important function as a paracrine hormone in brown adipose tissue by coordinating lipolysis with blood flow, $\mathrm{O}_{2}$ delivery for thermogenesis, and removal of heat (15).

A number of studies point to the placenta, liver, and blood elements as important tissues of origin for adenosine. In humans, for example, adenosine is released from the placental cotyledons into the umbilical circulation $(9-10)$. The liver might also be expected to change its contribution to plasma adenosine because its blood flow and oxygenation level change markedly in the perinatal period with loss of the umbilical circulation.

Basal plasma adenosine concentrations are high in fetal sheep compared with the adult, averaging 3- to 5-fold more (11-12). During the simulation of birth in utero, fetal cooling is followed by a small decrease in adenosine (12), but during these procedures adenosine concentrations remain in the range known to have powerful antilipolytic activity in the adult. Of most relevance are changes after cord occlusion. At this time plasma adenosine levels decline $\sim 50 \%$ within 60 min (12), suggesting the placenta as a likely source of a significant fraction of circulating adenosine. The rapid decrease is consistent with a short half-life of adenosine in ovine plasma (13). Because appreciable increases in nonshivering thermogenesis occur after cord occlusion, these results are consistent with a role for adenosine in thermogenic regulation.

The results of these experiments do not pinpoint adenosine specifically as the physiologic regulator of thermogenesis in utero but rather merely indicate that it is capable of serving in such a role. Further work on the clearance of adenosine and its origin in the fetus is needed. Other regulators have been described. For instance, based on recent work, prostaglandin $E_{2}$ released from the placenta has been shown to be an inhibitor of brown fat thermogenesis in utero (7). It also declines rapidly in the immediate postpartum period and has powerful antilipolytic activity. Clearly, additional studies are needed to clarify the interactions among stimuli of brown fat thermogenesis such as norepinephrine and inhibitors, especially adenosine and prostaglandins, in the perinatal period.

Acknowledgments. The authors thank M. Vickers and C. Mallard for their skilled technical assistance.

\section{REFERENCES}

1. Power GG, Gunn TR, Johnston BM, Gluckman PD 1987 Oxygen supply and the placenta limit thermogenic responses in fetal sheep. J Appl Physiol 63:1896-1901

2. Klein AH, Reviczky A, Chou P, Padbury J, Fisher DA 1983 Development of brown adipose tissue thermogenesis in the ovine fetus and newborn. Endocrinology 112:1662-1666

3. Alexander G, Nicol D, Thorburn G 1973 Thermogenesis in prematurely delivered lambs. In: Comline KS, Cross KW, Dawes GS (eds) Fetal and Neonatal Physiology (Sir Joseph Barcroft Centenary Symposium). Cambridge University Press, Cambridge, UK, pp 410-417

4. Gunn TR, Ball KT, Gluckman PD 1991 Reversible umbilical cord occlusion: effects on thermogenesis in utero. Pediatr Res 30:513-517

5. Gunn TR, Ball KT, Power GG, Gluckman PD 1991 Factors influencing the initiation of nonshivering thermogenesis. Am J Obstet Gynecol 164:210-217

6. Power GG, Gunn TR, Johnston BM, Nichols G, Gluckman PD 1989 Umbilical cord occlusion but not increased $\mathrm{T}_{3}$ or norepinephrine stimulate brown adipose tissue thermogenesis in the fetal sheep. J Dev Physiol 11:171-177

7. Gunn TR, Ball KT, Gluckman PD 1993 Withdrawal of placental prostaglandins permits thermogeniz responses in fetal sheep brown adipose tissue. J Appl Physiol 74:998-1004

8. Alexander G, Stevens D 1980 Sympathetic innervation and the development of structure and function of brown adipose tissue: studies on lambs chemically sympathectomized in uters with 6-hydroxydopamine. J Dev Physiol 2:119-137

9. Sim MK, Maguire MH 1972 Presence of adenosine in human term placenta. Determination of adenosine content and pathways of adenosine metabolism. Circ Res 31:779-788

10. Slegel P, Kitagawa H, Maguire MH 1988 Determination of adenosine in fetal perfusates of human placental cotyledons using fluorescence derivatization and reversed-phase high-performance liquid chromatography. Ann Biochem 171:124134

11. Mentzer Jr RM, Ely SW, Lasley RD, Mainwaring RD, Wright Jr EM, Berne RM 1985 Hormonal role of adenosine in maintaining patency of the ductus arteriosus in fetal lambs. Ann Surg 2(12:223-230

12. Sawa R, Asakura H. Power GG 1991 Changes in plasma adenosine during simulated birth of fetal sheep. J Appl Physiol 70:1524-1528

13. van Belle H 1969 Uptake and deamination of adenosine by blood. Species differences, effect of $\mathrm{pH}$, ions, temperature, and metabolic inhibitors. Biochim Biophys Acta 192:124-132

14. Schimmel RJ, Ellict ME, Dehmel VC 1987 Interactions between adenosine and $\alpha_{1}$-adrenergic agonists in regulation of respiration in hamster brown adipocytes. Mol Pharmacol 32:26-3.3 
15. Woodward JA, Saggerson ED 1986 Effect of adenosine deaminase, $\mathbf{N}^{6}$. phenylisopropyladenosine and hypothyroidism on the responsiveness of rat brown adipocytes to noradrenaline. Biochem J 238:395-403

16. Gluckman PD, Gunn TR, Johnston BM, Quinn JP 1984 Manipulation of the temperature of the fetal lamb in utero. In: Nathanielsz PW (ed) Animal Models in Fetal Medicine. Perinatology Press, New York, pp 37-56

17. Falholt K, Lund B, Falholt W 1973 An easy colorimetric micromethod for routine determination of free fatty acids in plasma. Clin Chim Acta 46:105-111

18. Pinter JK, Hayashi JA, Watson JA 1967 Enzymatic assay of glycerol, dehydroxyacetone and glyceraldehyde. Arch Biochem Biophys 121:404-414

19. Foster DO, Frydman ML 1978 Nonshivering thermogenesis in the rat. Il. Measurements of blood flow with microspheres point to brown adipose tissue as the dominant site of the calorigenesis induced by noradrenalin. Can J Physiol Pharmacol 56:110 122

20. Heim T, Hull D 1966 The effect of propranolol on the calorigenic response in brown adipose tissue of new-born rabbits to catecholamines, glucagon, corticotrophin and cold exposure. J Physiol 187:271-283

21. Michell B 1988 Transmembrane signalling. Trends Pharmacol Sci 9:130-134

22. Nedergaard J, Lindberg O 1982 The brown fat cell. Int Rev Cytol 74:187-286

23. Schimmel RJ, McCarthy L, Dzierzanowski D 1985 Effect of pertussis toxin treatment on metabolism in hamster brown adipocytes. Am J Physiol 249:C456-C463

24. Burnstock $G 1978$ A basis for distinguishing two types of purinergic receptor. In: Straub RW, Bolis L (eds) Cell Membrane Receptors for Drugs and Hormones: A Multidisciplinary Approach. Raven Press, New York, pp 107-118

25. Daly JW 1982 Adenosine receptors: targets for future drugs. J Med Chem 25:197-207
26. Stiles GL 1991 Adenosine receptors: physiological regulation and biochemical mechanisms. News Physiol Sci 6:161-165

27. Hoffman BB, Dall'Aglio E, Hollenbeck C, Chang H, Reaven GM 1986 Suppression of free fatty acids and triglycerides in normal and hypertriglyceridemic rats by the adenosine receptor agonist phenylisopropyladenosine. J Pharmacol Exp Ther 239:715-718

28. Westermann E, Stock K 1970 Inhibitors of lipolysis: potency and mode of action of $\alpha$ - and $\beta$-adrenolytics, methoxamine derivatives, prostaglandin $\mathrm{E}_{1}$ and phenylisopropyl adenosine. Horm Metab Res 2(suppl 2):47-54

29. Horwitz BA, Hamilton J 1984 Alpha-adrenergic-induced changes in hamster (Mesocricetus) brown adipocyte respiration and membrane potential. Comp Biochem Physiol 78C:99-104

30. Schimmel RJ, Dzierzanowskj D, Elliott ME, Honeyman TW 1986 Stimulation of phosphoinositide metabolism in hamster brown adipocytes exposed to $\alpha_{1}$-adrenergic agents and its inhibition with phorbol esters. Biochem J 236:757-764

31. Schimmel RJ, McCarthy L 1986 Effects of insulin, adenosine and prostaglandin on $\alpha$-adrenergic-stimulated respiration in brown adipocytes. Am J Physiol 250:C738C743

32. Mohell N, Wallace M, Fain JN 1984 Alpha-1-adrenergic stimulation of phosphatidylinositol turnover and respiration of brown fat cells. Mol Pharmacol 25:64-69

33. Schimmel RJ, McCarthy L, McMahon KK $1983 \alpha_{1}$-adrenergic stimulation of hamster brown adipocyte respiration. Am J Physiol 244:C362-C368

34. Schimmell RJ, McCarty L 1984 Role of adenosine as an endogenous regulator of respiration in hamster brown adipocytes. Am J Physiol 246:C301-C307 